Research Article

\title{
Multiobjective Optimization Design and Performance Prediction of Centrifugal Pump Based on Orthogonal Test
}

\author{
Yuqin Wang $\mathbb{D}$ and Xinwang Huo \\ College of Mechanical and Electronic Engineering, Chaohu University, Chaohu, Anhui 238000, China \\ Correspondence should be addressed to Yuqin Wang; wyqll1@126.com
}

Received 17 September 2017; Accepted 7 November 2017; Published 28 February 2018

Academic Editor: Fernando Lusquiños

Copyright (C) 2018 Yuqin Wang and Xinwang Huo. This is an open access article distributed under the Creative Commons Attribution License, which permits unrestricted use, distribution, and reproduction in any medium, provided the original work is properly cited.

In order to improve the hydraulic performance of the centrifugal pump, based on the original model, the optimization mathematical model with the four indexes head, efficiency, shaft power, and pump net positive suction head as objective function was established, and the multiobjective optimization design of the centrifugal pump was carried out by orthogonal test. Based on the $L_{16}\left(4^{4}\right)$ orthogonal table, 16 sets of orthogonal test schemes were made by selecting the four parameters impeller outlet width, blade inlet angle, blade outlet angle, and cape angle; the flow field numerical simulation was carried out by computational fluid dynamics technique; and the influence order of geometric parameters on optimization indexes was obtained by range analysis. The weight of each test factor on the optimization index was calculated by weight matrix, and a set of optimal schemes was obtained. Based on the external characteristic experimental bench of the IH 65-60-190 chemical centrifugal pump, the simulation values and test values of the prototype pump and the optimization pump were obtained under different working conditions. Under the rated flow, the head was reduced by $17.00 \%$, the efficiency was increased by $9.14 \%$, the shaft power was reduced by $21.50 \%$, the pump net positive suction head was reduced by $16.69 \%$, the curve hump was eliminated, the performance of centrifugal pump was improved, and the feasibility of the weight matrix optimization method was verified. The particle image velocimetry measurement system was used to measure the relative velocity of the internal media in the centrifugal pump. The results showed that the optimization pump had no obvious "jet-wake" flow structure, its maximum velocity was less than the prototype pump, the area of low-speed zone was larger than the prototype pump, the efficiency of the centrifugal pump was improved, and the shaft power and pump net positive suction head were reduced. The reason of the head decrease was analyzed from the internal flow situation, and the accuracy of the design optimization process was proved.

\section{Introduction}

Centrifugal pumps are widely used in various fields of national economy and play an important role in the fields of petroleum, chemical industry, national defense, and aerospace [1]. For a long time, how to solve the low efficiency of the centrifugal pump, the head flow curve prone to hump, and poor anticavitation performance is an important index to meet the need of the centrifugal pump design [2]. Centrifugal pumps are mainly based on the velocity coefficient method, extreme value loss method, criterion screening method, flow field analysis method, and other methods for hydraulic design and model conversion [3-6]. With the development of computer technology, CFD (computational fluid dynamics) technology has become an important means to predict the performance of the pump and shorten the development cycle. Haifeng et al. [7] used the pressure correction method to simulate the turbulent flow in the impeller of two centrifugal pumps, and through comparative analysis of the calculation results and experimental data, provided valuable information for the comparison and selection of the impeller scheme. Yanshu et al. [8] used G-A (genetic algorithm) to predict the performance of the centrifugal pump; compared with the BP (back propagation) network prediction algorithm, the sample training time was reduced, which was more suitable for engineering application. Wang et al. [9] used neural network to improve the fuzzy rules of centrifugal pump control 
system and achieved better control effect. Tan Lei et al. [10] proposed a new hydraulic design method for 3D guide vane of centrifugal pump, which improved the hydraulic performance of the centrifugal pump under nondesigned working conditions. For the performance of composite impeller centrifugal pump prediction, Shouqi et al. [11] used the improved BP neural network, introduced LevenbergMarquardt and other optimization algorithms, and discovered that the predicted value and experimental values had good consistency. Lei et al. [3] used the direct and inverse iterative design methods to design the centrifugal pump impeller, which improved the pump working efficiency compared with the traditional design method. Fu et al. [12] established a multiobjective mathematical optimization model with the highest efficiency of the lowspecific speed centrifugal pump, the minimum $\mathrm{NPSH}_{r}$ (pump net positive suction head), and the maximum theoretical head, and the genetic algorithm was used to solve the multiobjective mathematical optimization model and achieved good optimization effect.

In this paper, the orthogonal test is used to optimize the structural parameters of the centrifugal pump; combined with CFD numerical simulation, the influence of the main structural parameters of the impeller on the pump head, efficiency, shaft power, and $\mathrm{NPSH}_{r}$ is studied, and the optimal combination of parameters is calculated by weight matrix, in order to improve the hydraulic performance of the centrifugal pump.

\section{Centrifugal Pump Hydraulic Design}

The basic parameters of the centrifugal pump are flow rate $Q=25 \mathrm{~m}^{3} / \mathrm{h}$, head $H=50 \mathrm{~m}$, and rotational speed $n=2900 \mathrm{r} / \mathrm{min}$. The hydraulic design of the main structural parameters of the impeller is carried out by the velocity coefficient method [13], and the initial design scheme of the impeller is obtained as shown in Table 1.

According to the initial results in Table 1, the threedimensional model of the impeller can be obtained by using CFturbo software, as shown in Figure 1.

\section{Orthogonal Test Program Design}

3.1. Orthogonal Test Factors. Orthogonal test is a design method of using the orthogonal table to arrange and analyze the multifactor test $[14,15]$. It is from the whole level combination of test factors, the selection of some representative horizontal combination to carry on the test, through the analysis of this part of the test results, to understand the situation of comprehensive test, to find out the optimal level combination. Its basic characteristic is to use partial test instead of comprehensive test, and it is an efficient, fast, and economical experimental design method.

Considering the influence of impeller geometry parameters on the centrifugal pump head, efficiency, shaft power, and $\mathrm{NPSH}_{r}$, the impeller outlet width, inlet angle, outlet angle, and cape angle are selected as test factors, and four levels are set for each factor, as shown in Table 2.
TABLE 1: The main structural parameters of the impeller.

\begin{tabular}{lcc}
\hline Parameters & $\begin{array}{c}\text { Calculation } \\
\text { results }\end{array}$ & $\begin{array}{c}\text { Final } \\
\text { results }\end{array}$ \\
\hline Impeller inlet diameter, $D_{1}(\mathrm{~mm})$ & 59.5 & 60 \\
Impeller outlet diameter, $D_{2}(\mathrm{~mm})$ & $182.6-187.6$ & 190 \\
Impeller inlet width, $b_{1}(\mathrm{~mm})$ & 13.5 & 14 \\
Impeller outlet width, $b_{2}(\mathrm{~mm})$ & $4.5-5$ & 5 \\
Blade inlet angle, $\beta_{1}\left({ }^{\circ}\right)$ & $23-40$ & 30 \\
Blade outlet angle, $\beta_{2}\left({ }^{\circ}\right)$ & $16-40$ & 30 \\
Blade thickness, $S(\mathrm{~mm})$ & 2.4 & 3 \\
Blade number, $Z$ & 6.25 & 6 \\
Cape angle, $\varphi\left({ }^{\circ}\right)$ & $90-130$ & 120 \\
\hline
\end{tabular}

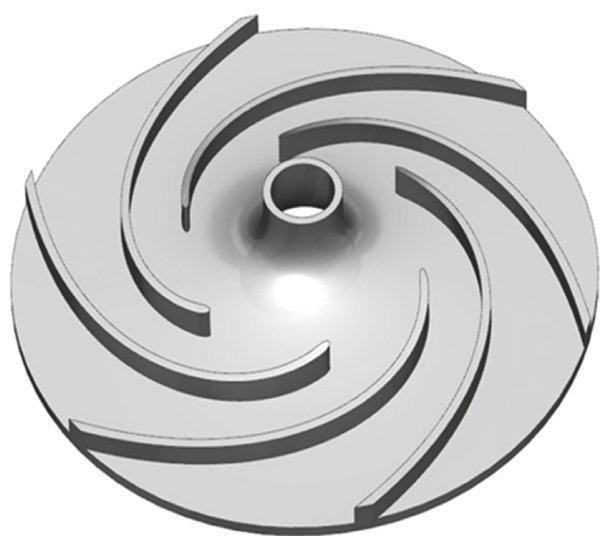

Figure 1: Impeller three-dimensional model.

TABLE 2: Level table of orthogonal test factors.

\begin{tabular}{lcccc}
\hline & \multicolumn{4}{c}{ Factors } \\
Levels & $A$ & $B$ & $C$ & $D$ \\
& $b_{2}(\mathrm{~mm})$ & $\beta_{1}\left({ }^{\circ}\right)$ & $\beta_{2}\left({ }^{\circ}\right)$ & $\varphi\left({ }^{\circ}\right)$ \\
\hline 1 & 7 & 23 & 20 & 95 \\
2 & 4 & 28 & 26 & 105 \\
3 & 5 & 33 & 32 & 115 \\
4 & 6 & 38 & 38 & 125 \\
\hline
\end{tabular}

In accordance with the $L_{16}\left(4^{4}\right)$ orthogonal table, 16 sets of orthogonal test schemes are established, as shown in Table 3.

\subsection{Numerical Simulation and Analysis}

3.2.1. Grid Division. PumpLinx is a simulation software for hydraulic simulation of pump research, which can accurately predict pressure, power, cavitation, heat transfer, flow, and other conditions. The impeller three-dimensional model is imported into PumpLinx software, and the unstructured grid can be divided, as shown in Figure 2.

As shown in Figure 2, the grid number of the impeller is 44,935. As a professional fluid mechanical analysis software, PumpLinx software can automatically select the appropriate mesh density for meshing. In order to further verify the 
TABLE 3: Orthogonal test schemes.

\begin{tabular}{lcccccccc}
\hline $\begin{array}{l}\text { Test serial } \\
\text { numbers }\end{array}$ & \multicolumn{3}{c}{ Factors } & \multicolumn{5}{c}{ Corresponding parameters } \\
\hline 1 & $A$ & $B$ & $C$ & $D$ & $b_{2}(\mathrm{~mm})$ & $\beta_{1}\left({ }^{\circ}\right)$ & $\beta_{2}\left({ }^{\circ}\right)$ & $\varphi\left({ }^{\circ}\right)$ \\
2 & $A_{1}$ & $B_{1}$ & $C_{1}$ & $D_{1}$ & 7 & 23 & 20 & 95 \\
3 & $A_{1}$ & $B_{2}$ & $C_{2}$ & $D_{2}$ & 7 & 28 & 26 & 105 \\
4 & $A_{1}$ & $B_{3}$ & $C_{3}$ & $D_{3}$ & 7 & 33 & 32 & 115 \\
5 & $A_{1}$ & $B_{4}$ & $C_{4}$ & $D_{4}$ & 7 & 38 & 38 & 125 \\
6 & $A_{2}$ & $B_{1}$ & $C_{2}$ & $D_{3}$ & 4 & 23 & 26 & 115 \\
7 & $A_{2}$ & $B_{2}$ & $C_{1}$ & $D_{4}$ & 4 & 28 & 20 & 125 \\
8 & $A_{2}$ & $B_{3}$ & $C_{4}$ & $D_{1}$ & 4 & 33 & 38 & 95 \\
9 & $A_{2}$ & $B_{4}$ & $C_{3}$ & $D_{2}$ & 4 & 38 & 32 & 105 \\
10 & $A_{3}$ & $B_{1}$ & $C_{3}$ & $D_{4}$ & 5 & 23 & 32 & 125 \\
11 & $A_{3}$ & $B_{2}$ & $C_{4}$ & $D_{3}$ & 5 & 28 & 38 & 115 \\
12 & $A_{3}$ & $B_{3}$ & $C_{1}$ & $D_{2}$ & 5 & 33 & 20 & 105 \\
13 & $A_{3}$ & $B_{4}$ & $C_{2}$ & $D_{1}$ & 5 & 38 & 26 & 95 \\
14 & $A_{4}$ & $B_{1}$ & $C_{4}$ & $D_{2}$ & 6 & 23 & 38 & 105 \\
15 & $A_{4}$ & $B_{2}$ & $C_{3}$ & $D_{1}$ & 6 & 28 & 32 & 95 \\
16 & $A_{4}$ & $B_{3}$ & $C_{2}$ & $D_{4}$ & 6 & 33 & 26 & 125 \\
\hline
\end{tabular}

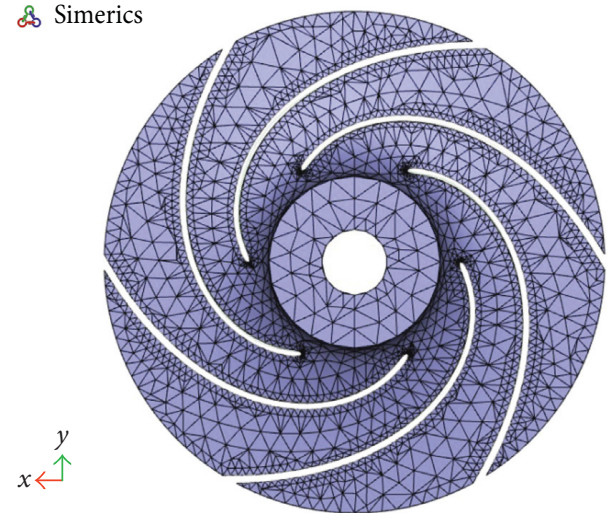

FIgURE 2: Impeller grid division.

influence of grid number on the numerical simulation performance of the centrifugal pump, the centrifugal pump outlet pressure is measured by changing the grid number, as shown in Figure 3.

As can be seen from Figure 3, with the increase in the grid number, although the outlet pressure of the centrifugal pump has changed, the change range is not large. It is visible that the grid density in the current situation does not have a greater impact on the numerical simulation results.

3.2.2. Boundary Conditions. Before numerical simulation, the boundary conditions of the centrifugal pump are set. Centrifugal pump boundary conditions are pump rotational speed, pump outlet flow rate, inlet pressure, turbulence model, and basic properties of fluid media. Among them, the pump rotational speed is $2900 \mathrm{r} / \mathrm{min}$, the pump outlet flow rate is $25 \mathrm{~m}^{3} / \mathrm{h}$, the inlet pressure is 1 atmosphere, and the $k-\varepsilon$ model is chosen for turbulence model.

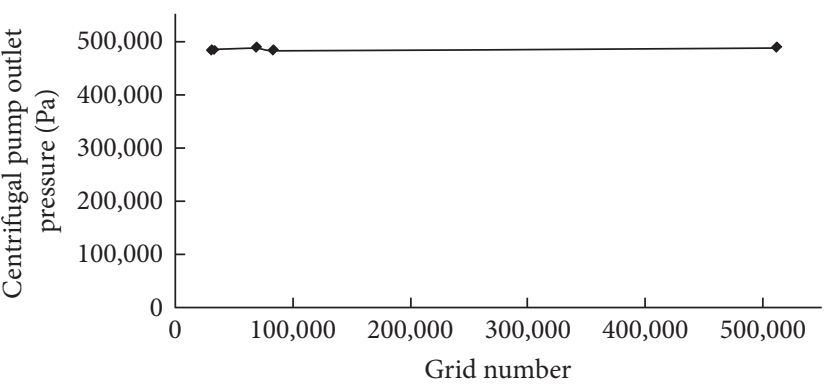

FIgURE 3: Distribution of centrifugal pump outlet pressure.

The basic properties of the fluid medium include density of the medium, reference temperature, kinematic viscosity, saturated vapor pressure, and volume elastic modulus. The basic parameters of fluid medium are set, as shown in Table 4 .

3.2.3. Control Equation. The control equations of the pump numerical calculation include the continuous equation, momentum equation (Navier-Stokes), and Reynolds equation. The numerical simulation medium of the centrifugal pump is water, which belongs to incompressible fluid, and its motion law is in accordance with the momentum equation.

The incompressible Navier-Stokes equation is the mathematical expression of momentum conservation law, and the tensor form of its differential equation is [16]

$$
\frac{\partial u_{i}}{\partial t}+u_{j} \frac{\partial u_{i}}{\partial x_{j}}=f_{i}-\frac{1}{\rho} \frac{\partial p}{\partial x_{i}}+v \frac{\partial^{2} u_{i}}{\partial x_{j} \partial x_{j}}
$$

In (1), $u_{i}$ is the velocity component parallel to the axis $x_{i}$, $t$ is the time, $f_{i}$ is the mass force on the unit volume fluid, $\rho$ is the fluid density, $p$ is the pressure, and $v$ is the kinetic viscosity. 
TABLE 4: Basic parameters of fluid media.

\begin{tabular}{lc}
\hline Parameters & Parameter values \\
\hline Fluid medium & Water \\
Density & $998.2 \mathrm{~kg} / \mathrm{m}^{3}$ \\
Reference temperature & $20^{\circ} \mathrm{C}$ \\
Kinematic viscosity & $1 \times 10^{-6} \mathrm{~m}^{2} / \mathrm{s}$ \\
Saturated vapor pressure & $2338.8 \mathrm{~Pa}$ \\
Volume elastic modulus & $2.18 \times 10^{9}$ \\
\hline
\end{tabular}

TABle 5: Orthogonal test results.

\begin{tabular}{lcccc}
\hline Test serial numbers & $H(\mathrm{~m})$ & $\eta(\%)$ & $P(\mathrm{~W})$ & $\mathrm{NPSH}_{r}(\mathrm{~m})$ \\
\hline 1 & 45.05 & 74.75 & 4094 & 1.297851 \\
2 & 44.65 & 74.56 & 4068 & 1.286662 \\
3 & 44.26 & 73.86 & 4071 & 1.275654 \\
4 & 43.03 & 70.30 & 4158 & 1.240883 \\
5 & 36.25 & 80.59 & 3056 & 1.049084 \\
6 & 33.10 & 82.45 & 2727 & 0.959460 \\
7 & 39.01 & 77.96 & 3399 & 1.127119 \\
8 & 36.34 & 77.20 & 3198 & 1.051548 \\
9 & 40.41 & 76.79 & 3575 & 1.166883 \\
10 & 41.61 & 75.63 & 3738 & 1.200818 \\
11 & 39.17 & 77.56 & 3431 & 1.131733 \\
12 & 39.80 & 75.23 & 3594 & 1.149505 \\
13 & 45.25 & 76.35 & 4026 & 1.303545 \\
14 & 44.32 & 75.80 & 3972 & 1.277401 \\
15 & 40.43 & 74.89 & 3668 & 1.167473 \\
16 & 39.02 & 73.64 & 3600 & 1.127533 \\
\hline
\end{tabular}

3.2.4. Orthogonal Test Results. The 16 sets of experimental data in Table 3 are numerically simulated by PumpLinx software. The pump head, efficiency, shaft power, and $\mathrm{NPSH}_{r}$ are calculated by (2) [17]. The orthogonal test results are shown in Table 5:

$$
\begin{aligned}
H & =\frac{\Delta P}{\rho g}, \\
\eta & =\frac{Q}{1000 P} \Delta P, \\
P & =\frac{\rho g Q H}{1000 \eta}, \\
\mathrm{NPSH}_{r} & =8.37\left(\frac{n_{s}}{100}\right)^{1.43}\left(\frac{H}{100}\right)^{0.98},
\end{aligned}
$$

where $g$ is the gravity acceleration, $P$ is the shaft power, $\Delta P$ is the inlet and outlet pressure difference, $\eta$ is the efficiency, and $n_{s}$ is the specific speed.

3.2.5. Range Analysis. Equation (3) is the range analysis formula, $E_{j}$ is the value of a certain factor, $K_{i}$ is the sum of factor values of $j$ levels, $k_{i}$ is the average of each factor, and $s_{i}$
TABLE 6: Influence analysis of parameters on the head.

\begin{tabular}{lcccc}
\hline Parameters & $b_{2}(\mathrm{~mm})$ & $\beta_{1}\left(^{\circ}\right)$ & $\beta_{2}\left(^{\circ}\right)$ & $\varphi\left(^{\circ}\right)$ \\
\hline$K_{1}$ & 176.99 & 166.96 & 156.34 & 168.18 \\
$K_{2}$ & 144.70 & 163.68 & 161.14 & 165.41 \\
$K_{3}$ & 161.00 & 162.87 & 165.34 & 161.15 \\
$K_{4}$ & 169.03 & 158.19 & 168.90 & 156.97 \\
$k_{1}$ & 44.25 & 41.74 & 39.08 & 42.04 \\
$k_{2}$ & 36.18 & 40.92 & 40.28 & 41.35 \\
$k_{3}$ & 40.25 & 40.72 & 41.33 & 40.29 \\
$k_{4}$ & 42.26 & 39.55 & 42.22 & 39.24 \\
$s$ & 8.07 & 2.19 & 3.14 & 2.80 \\
Sorting & 1 & 4 & 2 & 3 \\
\hline
\end{tabular}

is the range $[18,19]$. In general, the greater the $k_{i}$, the higher the indicators under this level. The larger the $s_{i}$, the greater the influence of this factor on the performance of the centrifugal pump:

$$
\begin{aligned}
K_{i} & =\sum_{j=1}^{4} E_{j}, \\
k_{i} & =\frac{1}{4} \sum_{j=1}^{4} E_{j}, \\
s_{i} & =k_{i \max }-k_{i \min } .
\end{aligned}
$$

Equation (3) is used to carry out the range analysis of orthogonal test results. The analysis results are shown in Tables 6-9.

From the range analysis of Table 6 , it can be concluded that the primary and secondary order of influence of each parameter on the pump head is $A C D B$. The optimal combination of the pump head as the evaluation criterion is $A_{1} B_{1} C_{4} D_{1}$, namely, $b_{2}=7, \beta_{1}=23^{\circ}, \beta_{2}=38^{\circ}$, and $\varphi=95^{\circ}$.

From the range analysis of Table 7 , it can be concluded that the primary and secondary order of influence of each parameter on the pump efficiency is $A B C D$. The optimal combination of pump efficiency as the evaluation criterion is $A_{2} B_{1} C_{1} D_{2}$, namely, $b_{2}=4, \beta_{1}=23^{\circ}, \beta_{2}=20^{\circ}$, and $\varphi=105^{\circ}$.

From the range analysis of Table 8 , it can be concluded that the primary and secondary order of influence of each parameter on the pump shaft power is $A C D B$. The optimal combination of pump shaft power as the evaluation criterion is $A_{2} B_{2} C_{1} D_{4}$, namely, $b_{2}=4, \beta_{1}=28^{\circ}, \beta_{2}=20^{\circ}$, and $\varphi=125^{\circ}$.

From the range analysis of Table 9 , it can be concluded that the primary and secondary order of influence of each parameter on the $\mathrm{NPSH}_{r}$ is $A C D B$. The optimal combination of $\mathrm{NPSH}_{r}$ as the evaluation criterion is $A_{2} B_{4} C_{1} D_{4}$, namely, $b_{2}=4, \beta_{1}=38^{\circ}, \beta_{2}=20^{\circ}$, and $\varphi=125^{\circ}$.

\section{Multiobjective Weighted Matrix Optimization Design}

According to the above orthogonal test, the optimal scheme of the four indexes head, efficiency, shaft power, and $\mathrm{NPSH}_{r}$ 
TABLE 7: Influence analysis of parameters on the efficiency.

\begin{tabular}{lcccc}
\hline Parameters & $b_{2}(\mathrm{~mm})$ & $\beta_{1}\left(^{\circ}\right)$ & $\beta_{2}\left({ }^{\circ}\right)$ & $\varphi\left(^{\circ}\right)$ \\
\hline$K_{1}$ & 293.47 & 308.48 & 308.39 & 303.74 \\
$K_{2}$ & 318.20 & 308.44 & 305.27 & 305.67 \\
$K_{3}$ & 305.21 & 304.27 & 303.65 & 303.71 \\
$K_{4}$ & 300.68 & 296.36 & 300.24 & 304.43 \\
$k_{1}$ & 73.37 & 77.12 & 77.10 & 75.94 \\
$k_{2}$ & 79.55 & 77.11 & 76.32 & 76.42 \\
$k_{3}$ & 76.30 & 76.07 & 75.91 & 75.93 \\
$k_{4}$ & 75.17 & 74.09 & 75.06 & 76.11 \\
$s$ & 6.18 & 3.03 & 2.04 & 0.49 \\
Sorting & 1 & 2 & 3 & 4 \\
\hline
\end{tabular}

TABLE 8: Influence analysis of parameters on the shaft power.

\begin{tabular}{lcccc}
\hline Parameters & $b_{2}(\mathrm{~mm})$ & $\beta_{1}\left(^{\circ}\right)$ & $\beta_{2}\left(^{\circ}\right)$ & $\varphi\left(^{\circ}\right)$ \\
\hline$K_{1}$ & 16,391 & 14,751 & 13,852 & 15,059 \\
$K_{2}$ & 12,380 & 14,505 & 14,386 & 14,723 \\
$K_{3}$ & 14,338 & 14,569 & 14,816 & 14,465 \\
$K_{4}$ & 15,266 & 14,550 & 15,321 & 14,128 \\
$k_{1}$ & 4098 & 3688 & 3463 & 3765 \\
$k_{2}$ & 3095 & 3626 & 3597 & 3681 \\
$k_{3}$ & 3585 & 3642 & 3704 & 3616 \\
$k_{4}$ & 3817 & 3638 & 3830 & 3532 \\
$s$ & 1003 & 62 & 367 & 233 \\
Sorting & 1 & 4 & 2 & 3 \\
\hline
\end{tabular}

TABLE 9: Influence analysis of parameters on the $\mathrm{NSPH}_{r}$.

\begin{tabular}{lcccc}
\hline Parameters & $b_{2}(\mathrm{~mm})$ & $\beta_{1}\left({ }^{\circ}\right)$ & $\beta_{2}\left(^{\circ}\right)$ & $\varphi\left(^{\circ}\right)$ \\
\hline$K_{1}$ & 5.101050 & 4.817363 & 4.516576 & 4.851875 \\
$K_{2}$ & 4.187211 & 4.724340 & 4.652724 & 4.773488 \\
$K_{3}$ & 4.648938 & 4.701979 & 4.771485 & 4.653088 \\
$K_{4}$ & 4.875952 & 4.569469 & 4.872365 & 4.534699 \\
$k_{1}$ & 1.275263 & 1.204341 & 1.129144 & 1.212969 \\
$k_{2}$ & 1.046803 & 1.181085 & 1.163181 & 1.193372 \\
$k_{3}$ & 1.162234 & 1.175495 & 1.192871 & 1.163272 \\
$k_{4}$ & 1.218988 & 1.142367 & 1.218091 & 1.133675 \\
$s$ & 0.228460 & 0.061973 & 0.088947 & 0.079294 \\
Sorting & 1 & 4 & 2 & 3 \\
\hline
\end{tabular}

is solved, respectively. However, the optimal scheme obtained by this method is independent and does not take into account the optimization scheme of multiple objectives. In order to effectively solve the above problems, based on the orthogonal test results, the weight matrix is used to calculate the influence degree of each test factors on each index, through comparative weight to determine the primary and secondary order of factors, and the optimal scheme is obtained [20].

According to the orthogonal test results of each factor, the matrices are established as shown in the following equation:

$$
\begin{aligned}
& M=\left[\begin{array}{ccccc}
\overline{K_{11}} & 0 & 0 & \ldots & 0 \\
\overline{K_{12}} & 0 & 0 & \ldots & 0 \\
\cdots & \ldots & \ldots & \ldots & \ldots \\
\overline{K_{1 m}} & 0 & 0 & \ldots & 0 \\
0 & \overline{K_{21}} & 0 & \ldots & 0 \\
0 & \overline{K_{22}} & 0 & \ldots & 0 \\
\cdots & \ldots & \ldots & \ldots & \ldots \\
0 & \overline{K_{2 m}} & 0 & \ldots & 0 \\
\cdots & \ldots & \ldots & \ldots & \ldots \\
0 & 0 & 0 & \ldots & \overline{K_{l 1}} \\
0 & 0 & 0 & \ldots & \overline{K_{l 2}} \\
\cdots & \ldots & \ldots & \ldots & \ldots \\
0 & 0 & 0 & \ldots & \overline{K_{l m}}
\end{array}\right], \\
& T=\left[\begin{array}{cccc}
T_{1} & 0 & 0 & 0 \\
0 & T_{2} & 0 & 0 \\
\cdots & \cdots & \cdots & \ldots \\
0 & 0 & 0 & T_{l}
\end{array}\right] \text {, } \\
& S=\left[\begin{array}{c}
S_{1} \\
S_{2} \\
\cdots \\
S_{l}
\end{array}\right] \text {. }
\end{aligned}
$$

In (4), the greater the value of head and efficiency, the better the control effect, then $\overline{K_{i j}}=k_{i j}$; the smaller the value of shaft power and $\mathrm{NPSH}_{r}$, the better the control effect, then $\overline{K_{i j}}=1 / k_{i j}$.

$$
\begin{aligned}
& \text { In (5), } T_{i}=1 / \sum_{j=1}^{m} \overline{K_{i j}} . \\
& \text { In (6), } S_{i}=s_{i} / \sum_{i=1}^{l} s_{i} .
\end{aligned}
$$

Thus, the weight matrix that affects the test index value is obtained as $\omega=\operatorname{MTS}=\left[\omega_{1}, \omega_{2}, \ldots, \omega_{m}\right]^{T}$.

According to the orthogonal test results, the weight matrix is calculated by calculating the weight matrix of each index, and the weight matrix $\omega_{\text {avg }}$ can be obtained by calculating the arithmetic mean of four indexes; the calculation results are as follows:

$$
\begin{aligned}
& \omega_{1}=[13.53,11.06,12.31,12.92,3.46,3.40,3.38,3.28,4.65 \text {, } \\
& 4.79,4.92,5.02,4.46,4.39,4.27,4.16]^{T} \times 10^{-2} \text {, } \\
& \omega_{2}=[12.69,13.76,13.20,13.00,6.54,6.54,6.45,6.28,4.40 \text {, } \\
& 4.36,4.33,4.28,1.04,1.05,1.04,1.04]^{T} \times 10^{-2}, \\
& \omega_{3}=[13.27,17.57,15.16,14.24,0.92,0.94,0.93,0.93,5.80 \text {, } \\
& 5.58,5.42,5.24,3.39,3.47,3.53,3.61]^{T} \times 10^{-2} \\
& \omega_{4}=[11.42,13.91,12.53,11.95,3.30,3.36,3.38,3.48,5.04 \text {, } \\
& 4.90,4.77,4.68,4.19,4.26,4.37,4.48]^{T} \times 10^{-2} \text {, } \\
& \omega_{\mathrm{avg}}=[12.728,14.075,13.300,13.028,3.555,3.560,3.535 \text {, } \\
& \text { 3.493, 4.973, 4.908, 4.860,4.805,3.270,3.293, } \\
& 3.303,3.323]^{T} \times 10^{-2} \text {. }
\end{aligned}
$$


From the weight matrix $\omega_{\text {avg, }}$, it can be seen that the primary and secondary order of the influence of each factor on the comprehensive performance of orthogonal test is $A C B D$, and the weights of factors $A_{2}, B_{2}, C_{1}$, and $D_{4}$ are the largest, so that the total optimal scheme can be determined as follows: $A_{2} B_{2} C_{1} D_{4}$, namely, $b_{2}=4, \beta_{1}=28^{\circ}, \beta_{2}=20^{\circ}$, and $\varphi=125^{\circ}$.

\section{Experimental Verification}

5.1. External Characteristics Test. In order to verify the feasibility of the optimization scheme, the external characteristics test bench is set up by the IH 65-60-190 chemical centrifugal pump, as shown in Figures 4 and 5. The IH 6560-190 chemical centrifugal pump is a single-stage singlesuction cantilever centrifugal pump, which can transport corrosive liquid. The chemical pump mainly consists of the pump body, blade transmission line, sealing ring, impeller nut, pump cover, sealing components, intermediate bracket, shaft, suspension components, and so on.

Based on the optimal scheme, the impeller is made of polyvinyl chloride (PVC), as shown in Figure 6. The external characteristics of the centrifugal pump are measured, respectively, under the 6 operating conditions $0.2 Q_{d}, 0.4 Q_{d}$, $0.6 Q_{d}, 0.8 Q_{d}, 1.0 Q_{d}$, and $1.2 Q_{d}$ (where the rated flow $Q_{d}=25 \mathrm{~m}^{3} / \mathrm{h}$ ), and the external characteristics curves of the simulated and experimental values of the centrifugal pump before and after optimization are shown in Figure 7.

As shown in Figure 7, although there are errors in the simulation and experimental results, the simulation values and experimental values of each index before and after optimization are consistent with the trend of the flow variation. The simulation values and the experimental values of each index parameter are in good agreement, which can accurately reflect the trend of the changes with the flow rate. The main reasons for the error of the simulation and experimental values are that the leakage of the mouth ring and the volume loss of the front and rear pump cavity are not considered in the numerical simulation, and the accuracy of the impeller model may also be different in the production process. The simulation values of head and efficiency are greater than the experimental values, the simulation value of shaft power is less than the experimental value, and the simulation value of $\mathrm{NPSH}_{r}$ is greater than the experimental value. Before and after optimization of $\beta_{2} Z^{0.773}$ are 119.85 and 79.90 , respectively. As the blade outlet angle is reduced, the $\beta_{2} Z^{0.773}<90$ is less than 90 and the curve hump is eliminated [11].

The experimental results before and after optimization of each index under different conditions are extracted from Figure 7, as shown in Table 10.

As shown in Table 10, at the rated flow, the pump head is reduced by $17.00 \%$, the efficiency is increased by $9.14 \%$, the shaft power is reduced by $21.50 \%$, and the $\mathrm{NPSH}_{r}$ is reduced by $16.69 \%$. Compared with the prototype pump, the optimization pump reduces the width of the impeller outlet, improves the efficiency, and reduces the head. In addition, because the optimization model reduces the blade outlet angle, the shaft power is reduced as a whole.

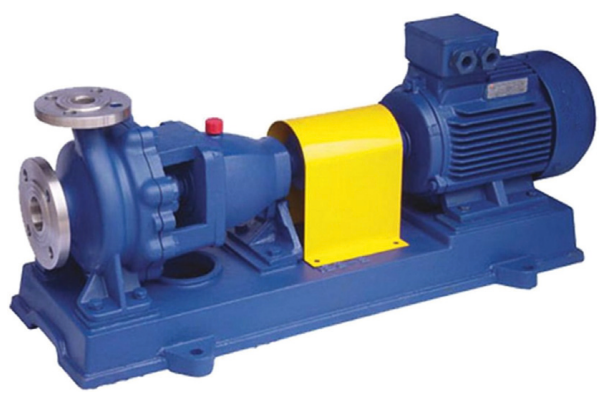

Figure 4: Test pump.

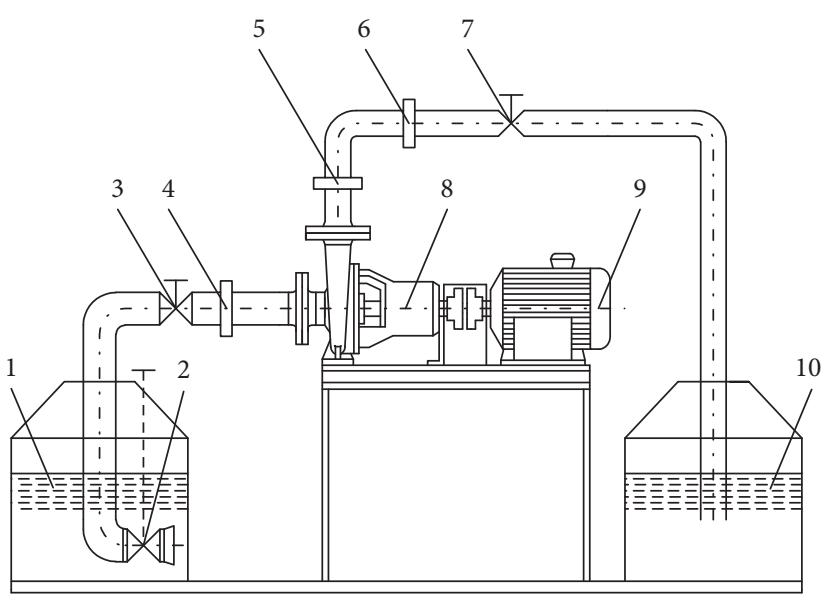

Figure 5: External characteristics test bench. (1) Water tank. (2) Vacuum control valve. (3) Inlet control valve. (4) Vacuum table. (5) Pressure gauge. (6) Flow meter. (7) Flow control valve. (8) Test pump. (9) Motor. (10) Water tank.

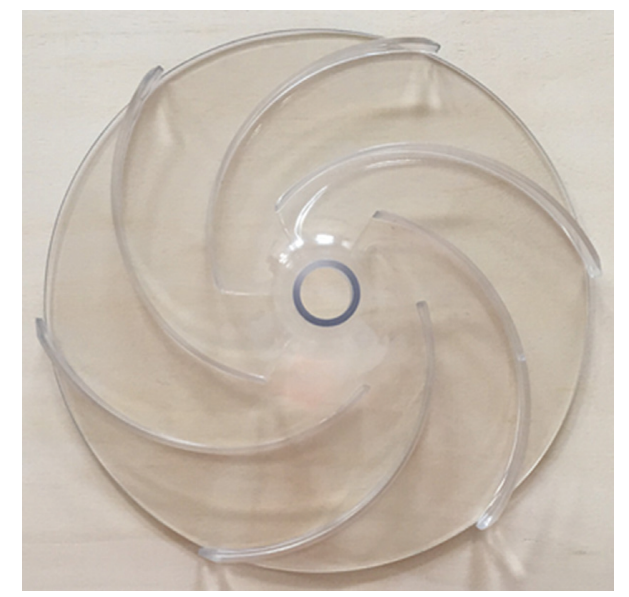

Figure 6: Test impeller.

The cape angle of optimization pump is increased, which increases the flow channel area, reduces the blade blocking, improves the fluid flow efficiency, and improves the anticavitation performance of the centrifugal pump. In summary, although the optimization results of individual indicators is not ideal, the performance of other indicators is significantly improved; it can be concluded that the weight matrix optimization method is feasible, and the 


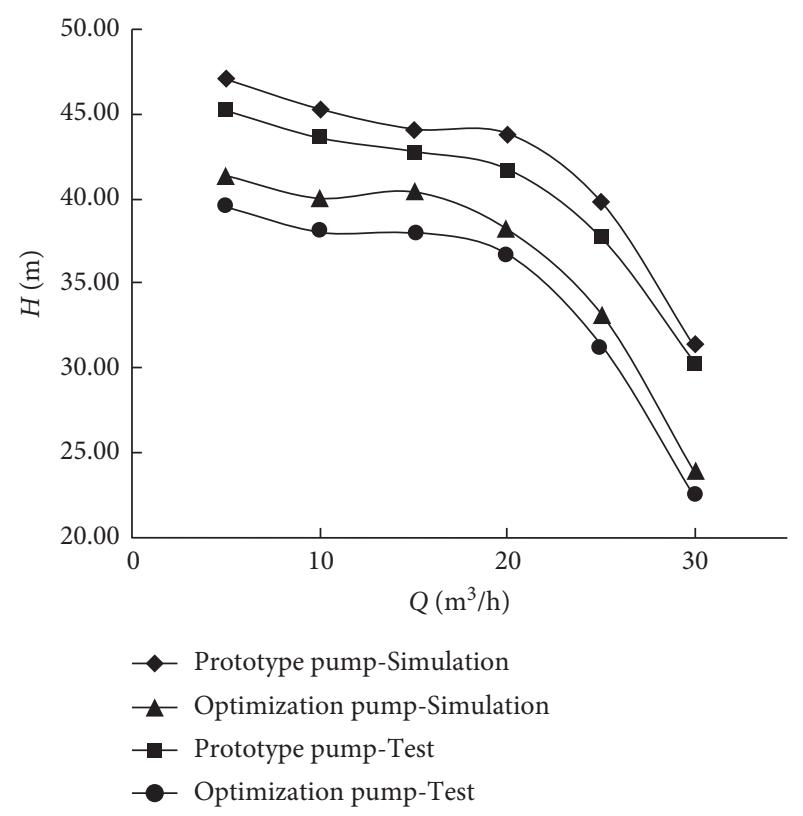

(a)

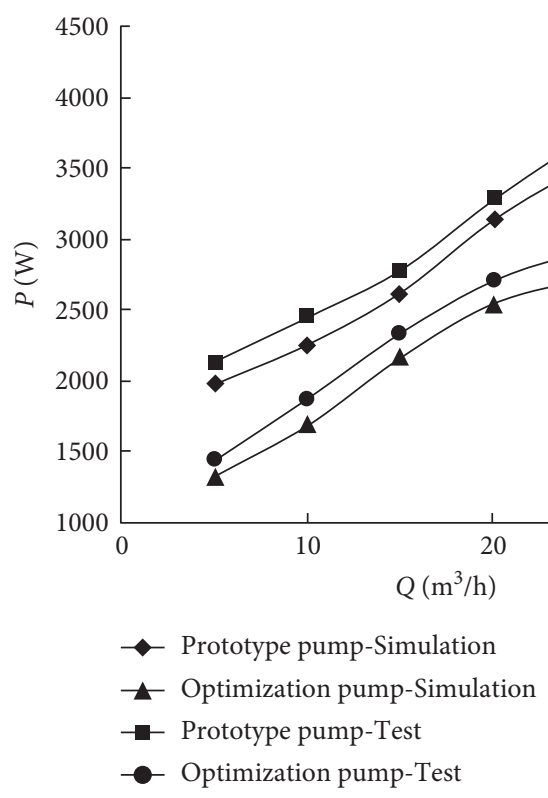

(c)

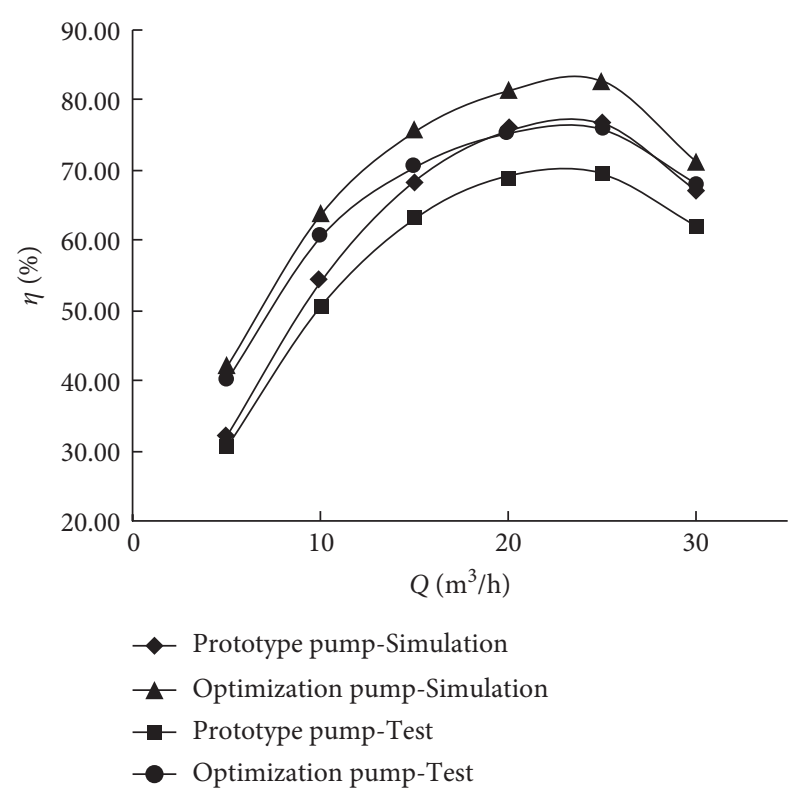

(b)

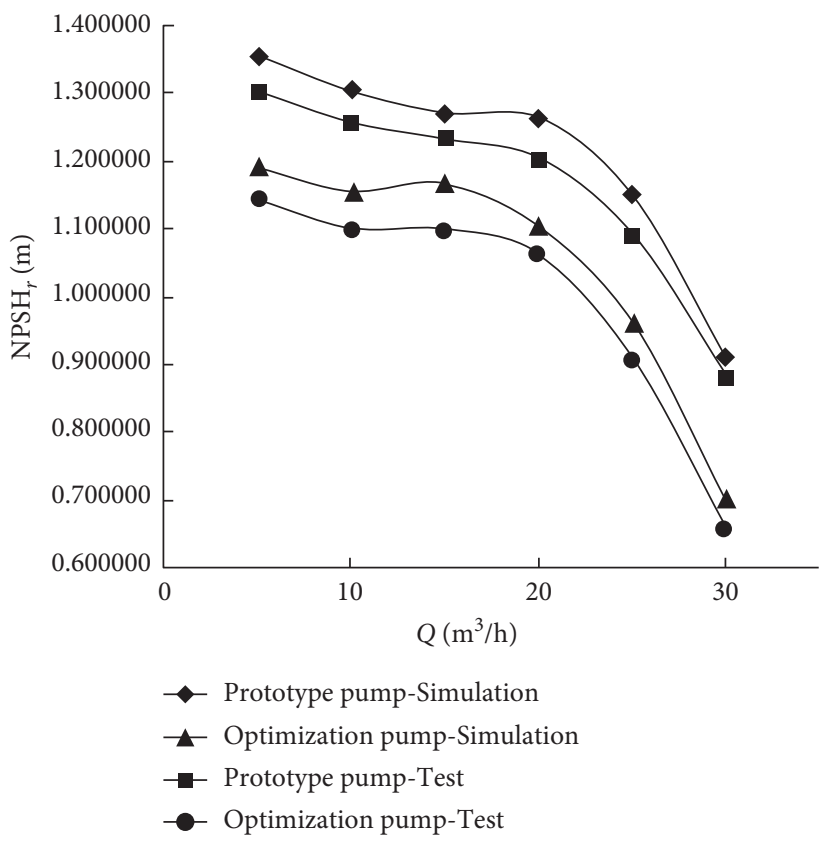

(d)

Figure 7: Comparison of external characteristics of optimization pump and prototype pump. (a) $H-Q$. (b) $\eta-Q$. (c) $P-Q$. (d) $N P S H_{r}-Q$.

internal flow field simulation and test of the centrifugal pump are accurate.

\subsection{PIV (Particle Image Velocimetry) Test on Internal Flow} Field. The changes of external characteristics of the centrifugal pump and $\mathrm{NPSH}_{r}$ are related to the internal flow field, and the internal flow field change is the intrinsic factor of the above characteristics. In order to further analyze the changes of flow field in the centrifugal pump before and after optimization, the centrifugal pump flow field test platform is built based on PIV measurement system, as shown in Figure 8 . The PIV system mainly includes pulse laser, CCD camera, image acquisition card, lens group, and encoder.

At fixed speed $(2900 \mathrm{r} / \mathrm{min})$, the flow field of centrifugal pump before and after optimization under rated flow condition is measured, and the relative velocity vector diagrams and cloud diagrams of the prototype pump and the optimization pump are shown in Figures 9 and 10, respectively. The fluid area between the two blades is shown in 
TABLE 10: Experimental results before and after optimization of each index.

\begin{tabular}{|c|c|c|c|c|c|c|}
\hline \multirow{2}{*}{ Indexes } & \multicolumn{6}{|c|}{$Q\left(\mathrm{~m}^{3} / \mathrm{h}\right)$} \\
\hline & 5 & 10 & 15 & 20 & 25 & 30 \\
\hline Before optimization, $H(\mathrm{~m})$ & 45.26 & 43.67 & 42.83 & 41.79 & 37.77 & 30.44 \\
\hline After optimization, $H(\mathrm{~m})$ & 39.58 & 38.12 & 38.06 & 36.74 & 31.35 & 22.56 \\
\hline$\Delta H(\%)$ & 12.55 & 12.71 & 11.14 & 12.08 & 17.00 & 25.89 \\
\hline Before optimization, $\eta(\%)$ & 30.96 & 50.77 & 63.34 & 69.22 & 69.69 & 62.25 \\
\hline After optimization, $\eta(\%)$ & 40.34 & 60.74 & 70.65 & 75.43 & 76.06 & 68.27 \\
\hline$\Delta \eta(\%)$ & 30.30 & 19.64 & 11.54 & 8.97 & 9.14 & 9.67 \\
\hline Before optimization, $P(\mathrm{~W})$ & 2137 & 2464 & 2786 & 3285 & 3712 & 4037 \\
\hline After optimization, $P(\mathrm{~W})$ & 1444 & 1885 & 2339 & 2717 & 2914 & 3026 \\
\hline$\Delta P(\%)$ & 32.43 & 23.50 & 16.04 & 17.29 & 21.50 & 25.04 \\
\hline Before optimization, $\mathrm{NPSH}_{r}(\mathrm{~m})$ & 1.303873 & 1.258968 & 1.235231 & 1.205830 & 1.092041 & 0.883916 \\
\hline After optimization, $\mathrm{NPSH}_{r}(\mathrm{~m})$ & 1.143303 & 1.101958 & 1.100258 & 1.062849 & 0.909804 & 0.659033 \\
\hline$\Delta \mathrm{NPSH}_{r}(\%)$ & 12.31 & 12.47 & 10.93 & 11.86 & 16.69 & 25.44 \\
\hline
\end{tabular}

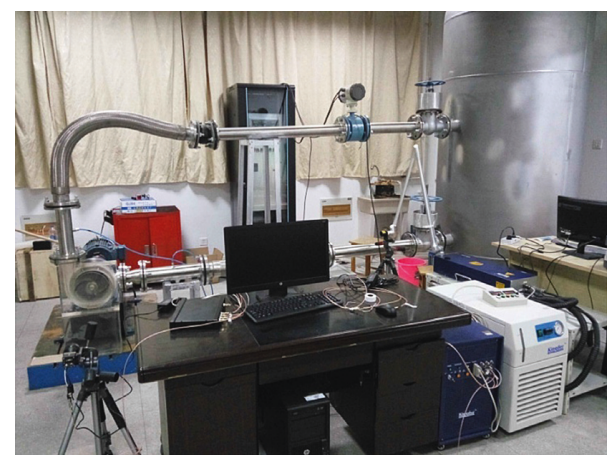

FIgURE 8: PIV system test platform.

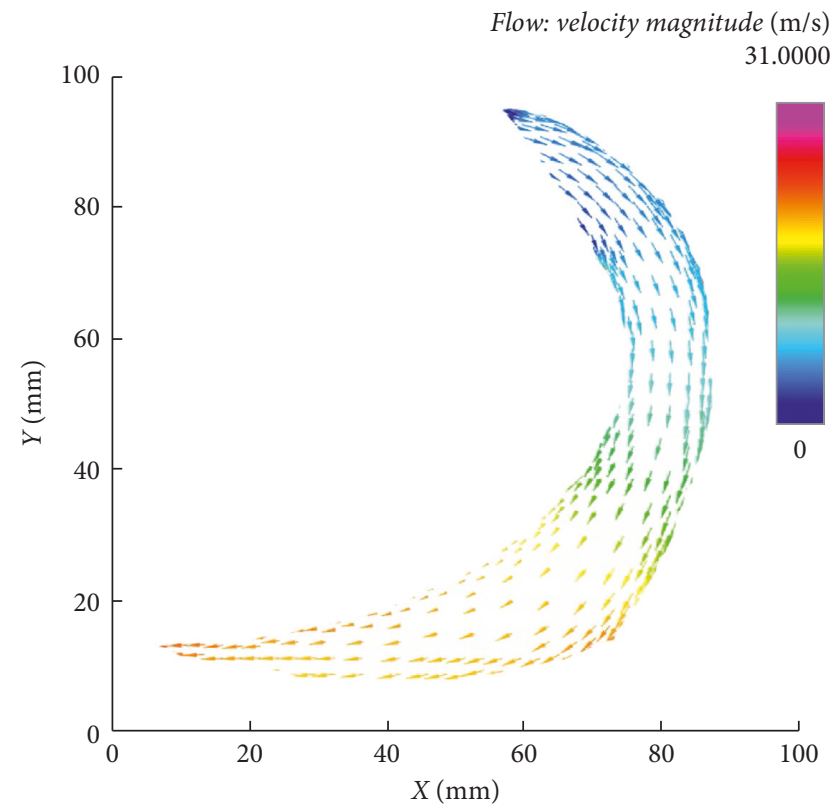

(a)

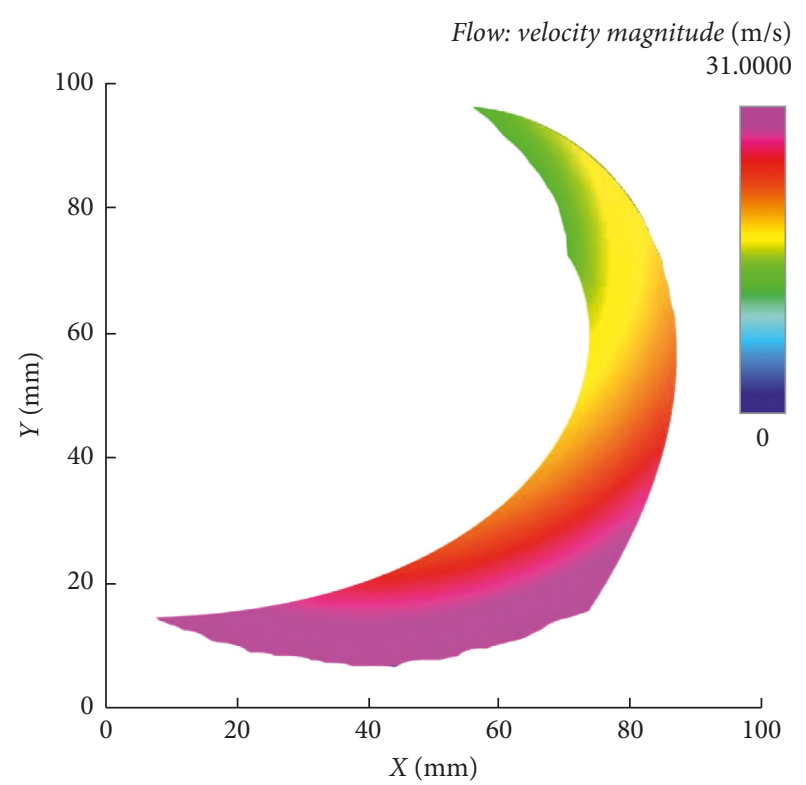

(b)

Figure 9: Prototype pump relative speed velocity (a) vector diagram and (b) cloud diagram. 


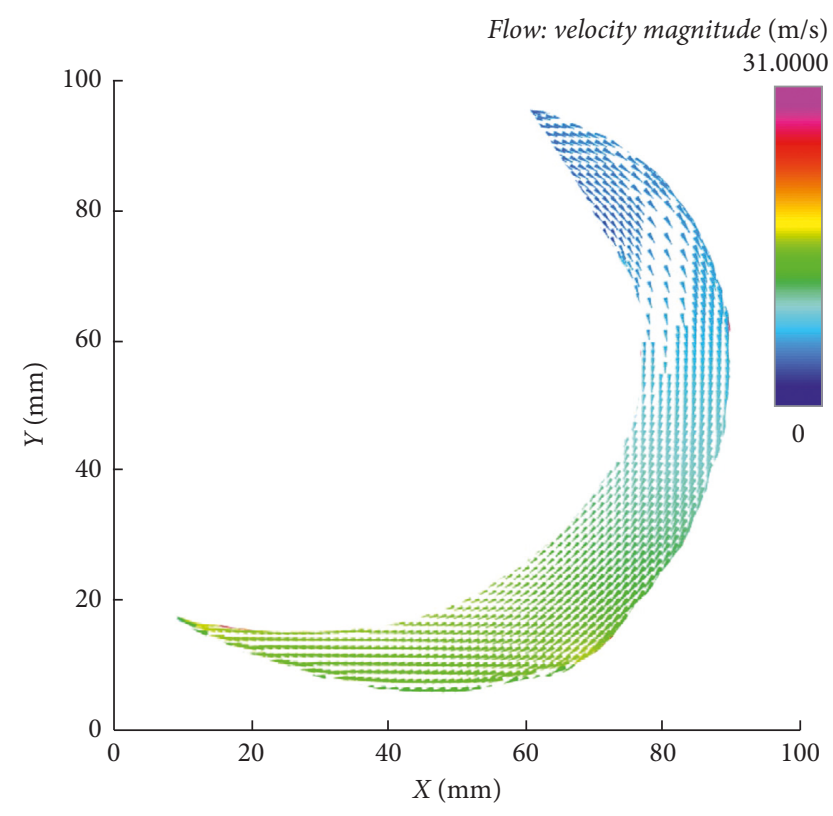

(a)

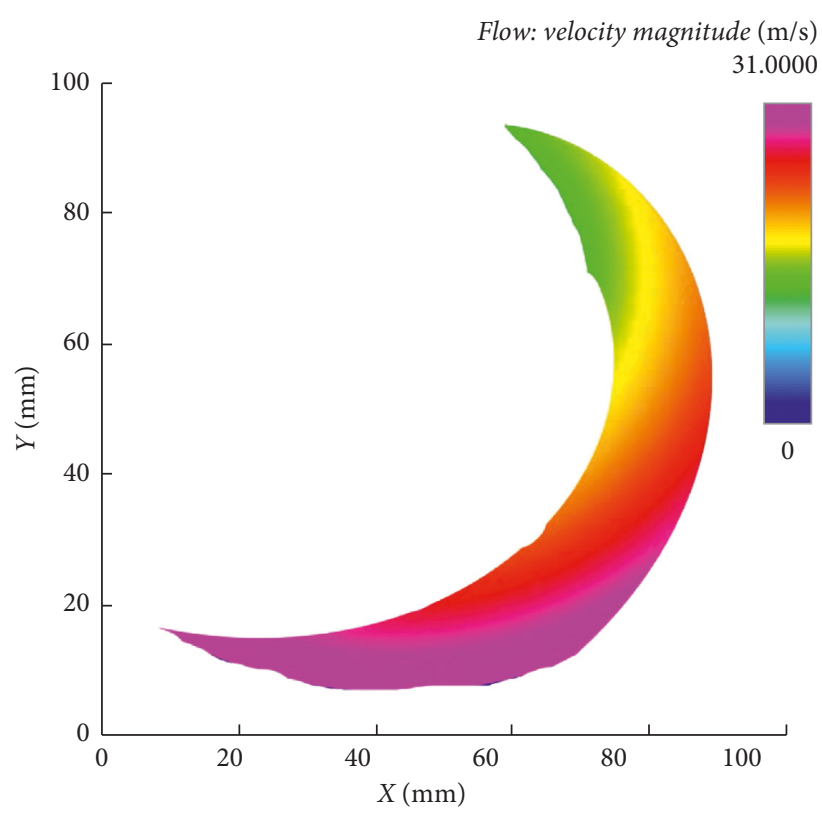

(b)

FIGURE 10: Optimization pump relative speed velocity (a) vector diagram and (b) cloud diagram.

the figure, the arrow represents the flow direction of the fluid, and the left and right edges of fluid area are two adjacent blades of the impeller. Since the semiopen impeller selected only has a back shroud, the blades are distributed on the back shroud. When the centrifugal pump is in the working state, the edge of the fluid flowing into the blade is the leading edge of the impeller and the edge of the fluid flowing out of the blade is the trailing edge of the impeller. The hub is located at the impeller inlet of the leading edge, which is installed at the center position on the back of back shroud and is assembled with pump shaft.

From Figures 9 and 10, the relative velocity of cross section in the impeller channel flows along the blade profile direction, the relative velocity of fluid from the center of the impeller to the edge of the impeller is gradually increased, the change of gradient is relatively flat, and there is no obvious "jet-wake" flow structure. The inlet of blade pressure surface of the prototype pump and the optimization pump has low velocity area, the relative velocity of working face is less than the back surface, and the maximum speed appears at the outlet of the back surface. The relevant data are extracted 5th page through Figures 9 and 10, the maximum velocity of the prototype pump is $30.8466 \mathrm{~m} / \mathrm{s}$, the maximum velocity of the optimization pump is $28.7978 \mathrm{~m} / \mathrm{s}$, and the optimization pump velocity is $6.64 \%$ smaller than the prototype pump. Because the optimization pump adopts the smaller impeller outlet width and the blade outlet angle, the optimization pump speed zone is larger than the prototype pump, the medium is more easily controlled in the flow channel, and the efficiency of centrifugal pump is improved significantly. In addition, when the optimization pump low-speed zone area is large, there will be a certain hydraulic loss and reduction in the head, which is consistent with the above external characteristics experimental results. At the same time, when the optimization pump blade inlet angle is small, the flow of internal media in centrifugal pump is more stable, and to some extent, the anticavitation resistance of centrifugal pump is improved, and the cavitation phenomenon is reduced.

\section{Conclusion}

(1) The velocity coefficient method was used to design the hydraulic design of the centrifugal pump, the main structure parameters of the impeller were obtained, and the three-dimensional model of the impeller was established by CFturbo software.

(2) The 16 sets of experimental schemes were designed by orthogonal test, the internal flow field of centrifugal pump was simulated by PumpLinx software, the weight matrix was used to optimize the head, efficiency, shaft power, and $\mathrm{NPSH}_{r}$, and the optimal scheme was obtained.

(3) To build the external characteristics test of the centrifugal pump, the simulation values and experimental values before and after optimization under different working conditions were obtained. The simulation values and experimental values of each index are consistent with the law of flow variation, the relative error of simulation value and experimental value was relatively small, the optimization of pump indexes except head had significant improvement, the curve hump was eliminated, and the feasibility of the weight matrix optimization method was verified.

(4) Based on the PIV test system, the experimental results show that there was no obvious "jet-wake" flow structure in the optimization pump, its maximum velocity was less than the prototype pump, the area of 
low-speed zone was larger than the prototype pump, the efficiency and anticavitation performance of centrifugal pump were improved, the head and shaft power were reduced, and the accuracy of the optimization design process was proved.

(5) Taking the centrifugal pump as the research object, the hydraulic performance of the centrifugal pump was improved by orthogonal test, which laid a foundation for the research of hydraulic design and external characteristics of the centrifugal pump. However, due to the limitations of the research conditions, there were still some deficiencies that need to be improved. In this paper, the weight matrix method was used to optimize the orthogonal test results, the influence of the impeller geometric parameters on the comprehensive performance of centrifugal pump was obtained by calculating the weight, and a set of optimal scheme was obtained. In the experimental results, although the performance of other indicators was significantly improved, the head was greatly reduced, which had a greater impact on the efficiency of pump. Therefore, in the followup work, the influence of the main geometric parameters of the impeller and shell on the hydraulic performance of the centrifugal pump will be comprehensively considered, in order to improve the overall performance of the centrifugal pump.

\section{Conflicts of Interest}

The authors declare that there are no conflicts of interest regarding the publication of this paper.

\section{Acknowledgments}

This project is supported by Key Project of Natural Science Research in Colleges and Universities of Anhui Province, China (KJ2017A450), Anhui Province University Outstanding Young Talent Support Program Project, China (gxyq2017071), and Natural Science Foundation of Chaohu University, China (XLZ-201503).

\section{References}

[1] W. Wenjie, Y. Shouqi, P. Ji, Z. Jinfeng, Y. Jianping, and M. Faliang, "Two-point hydraulic optimization of pump impeller based on kriging model and neighborhood cultivation genetic algorithm," Journal of Mechanical Engineering, vol. 51, no. 15, pp. 33-38, 2015, in Chinese.

[2] W. Xiaohua, R. Yi, D. Kan, and L. Xuehua, "Orthogonal test of factors for influencing efficiency of high speed pump," Process Equipment \& Piping, vol. 53, no. 2, pp. 43-45, 2016, in Chinese.

[3] L. Tan, S. Cao, Y. Wang, and B. Zhu, "Direct and inverse iterative design method for centrifugal pump impellers," Proceedings of the Institution of Mechanical Engineers, Part A: Journal of Power and Energy, vol. 226, no. 6, pp. 764-775, 2012.

[4] S. Kim, Y.-S. Choi, K.-Y. Lee, and J.-Y. Yoon, "Design optimization of centrifugal pump impellers in a fixed meridional geometry using DOE," International Journal of Fluid $\mathrm{Ma}$ chinery \& Systems, vol. 2, no. 2, pp. 172-178, 2009.
[5] N. R. Sakthivel, V. Sugumaran, and B. B. Nair, "Automatic rule learning using roughset for fuzzy classifier in fault categorization of mono-block centrifugal pump," Applied Soft Computing, vol. 12, no. 1, pp. 196-203, 2012.

[6] S. Derakhshan, M. Pourmahdavi, E. Abdolahnejad, A. Reihani, and A. Ojaghi, "Numerical shape optimization of a centrifugal pump impeller using artificial bee colony algorithm," Computers \& Fluids, vol. 81, no. 9, pp. 145-151, 2013.

[7] L. Haifeng, W. Yulin, and Z. Zhimei, "The determination of centrifugal pump impeller's design with three-dimensional turbulent flow simulation," Fluid Machinery, vol. 29, no. 9, pp. 18-21, 2001, in Chinese.

[8] Z. Yanshu, Z. Shisha, Z. Dazhou, and W. Cheng, "Predicting performance of centrifugal pump by combining genetic algorithm with BP neural network," Mechanical Science and Technology for Aerospace Engineering, vol. 31, no. 8, pp. 1274-1279, 2012, in Chinese.

[9] K. Wang and B. Lei, "Using B-spline neural network to extract fuzzy rules for a centrifugal pump monitoring," Journal of Intelligent Manufacturing, vol. 12, no. 1, pp. 5-11, 2001.

[10] T. Lei, C. Shuliang, and G. Shaobo, "Hydraulic design and prewhirl regulation law of inlet guide vane for centrifugal pump," Science China Technological Sciences, vol. 53, no. 8, pp. 2142-2151, 2010.

[11] Y. Shouqi, S. Yanning, Z. Jinfeng, and Y. Jianping, "Performance predicting of centrifugal pumps with compound impeller based on improved BP neural network," Transactions of the Chinese Society for Agricultural Machinery, vol. 40, no. 9, pp. 77-80, 2009, in Chinese.

[12] L. Fu and Z. Hong, "Optimization design of lower speed pump based on genetic algorithm," Journal of Chinese Agricultural Mechanization, vol. 37, no. 2, pp. 233-236, 2016, in Chinese.

[13] G. Xingfan, Theory and Design of Pump, Aerospace Press, Beijing, China, 2011, in Chinese.

[14] C. Xiaoqing, Z. Ri, H. Yongtao, and Y. Dan-Qing, "Optimization design of deep-well centrifugal pump based on CFX orthogonal test," Fluid Machinery, vol. 43, no. 9, pp. 22-25, 2015, in Chinese.

[15] X. Yun, T. Lei, C. Shuliang, and W. Qu, "Multiparameter and multiobjective optimization design of centrifugal pump based on orthogonal method," Proceedings of the Institution of Mechanical Engineers, Part C: Journal of Mechanical Engineering Science, vol. 231, no. 14, pp. 2569-2579, 2016.

[16] D. Liang and L. Houlin, Detailed Explanation of CFD Numerical Calculation for Vane Pump, China Machine Press, Beijing, China, 2015, in Chinese.

[17] L. Houlin and T. Minggao, Modern Design Methods for Centrifugal Pumps, China Machine Press, Beijing, China, 2013, in Chinese.

[18] W. Wei, S. Weidong, J. Xiaoping, F. Qi, L. Weigang, and Z. Desheng, "Optimization design of multistage centrifugal pump impeller by orthogonal experiment and CFD," Journal of Drainage and Irrigation Machinery Engineering, vol. 34, no. 3, pp. 191-197, 2016, in Chinese.

[19] S. Qiaorui, L. Gang, Y. Shouqi, and C. Rui, "Multi-objective optimization on hydraulic design of non-overload centrifugal pumps with high efficiency and low noise," Transactions of the Chinese Society of Agricultural Engineering, vol. 32, no. 4, pp. 69-77, 2016, in Chinese.

[20] W. Xiaoling, X. Bingjun, and Z. Qiang, "Optimization design of the stability for the plunger assembly of oil pumps based on multi-target orthogonal test design," Journal of Hebei University of Engineering, vol. 27, no. 3, pp. 95-99, 2010, in Chinese. 


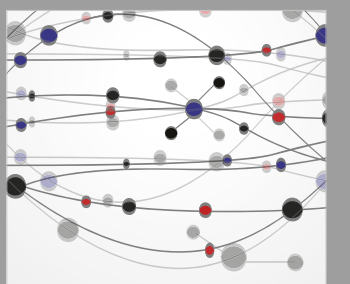

The Scientific World Journal
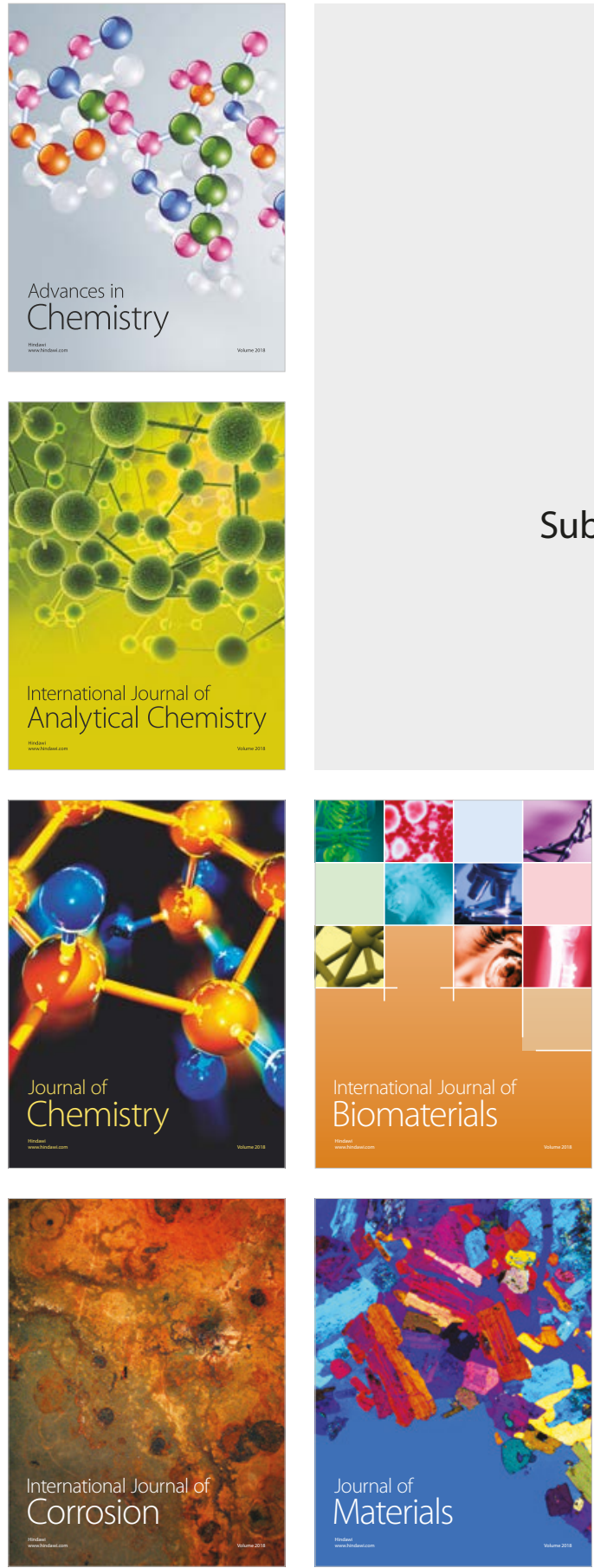

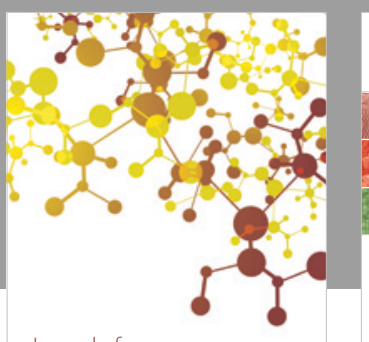

Journal of

Applied Chemistry
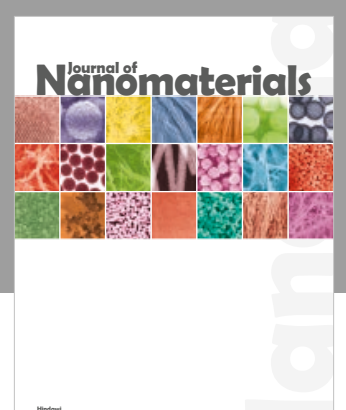

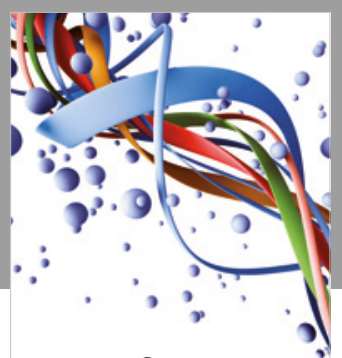

Scientifica

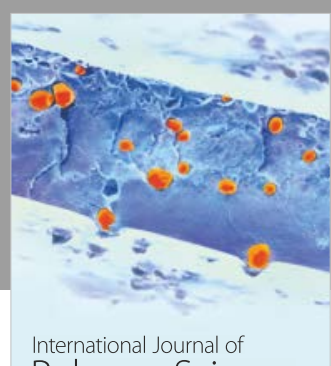

Polymer Science

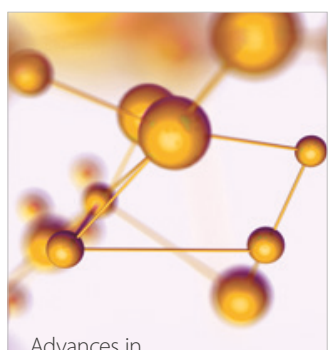

Physical Chemistry
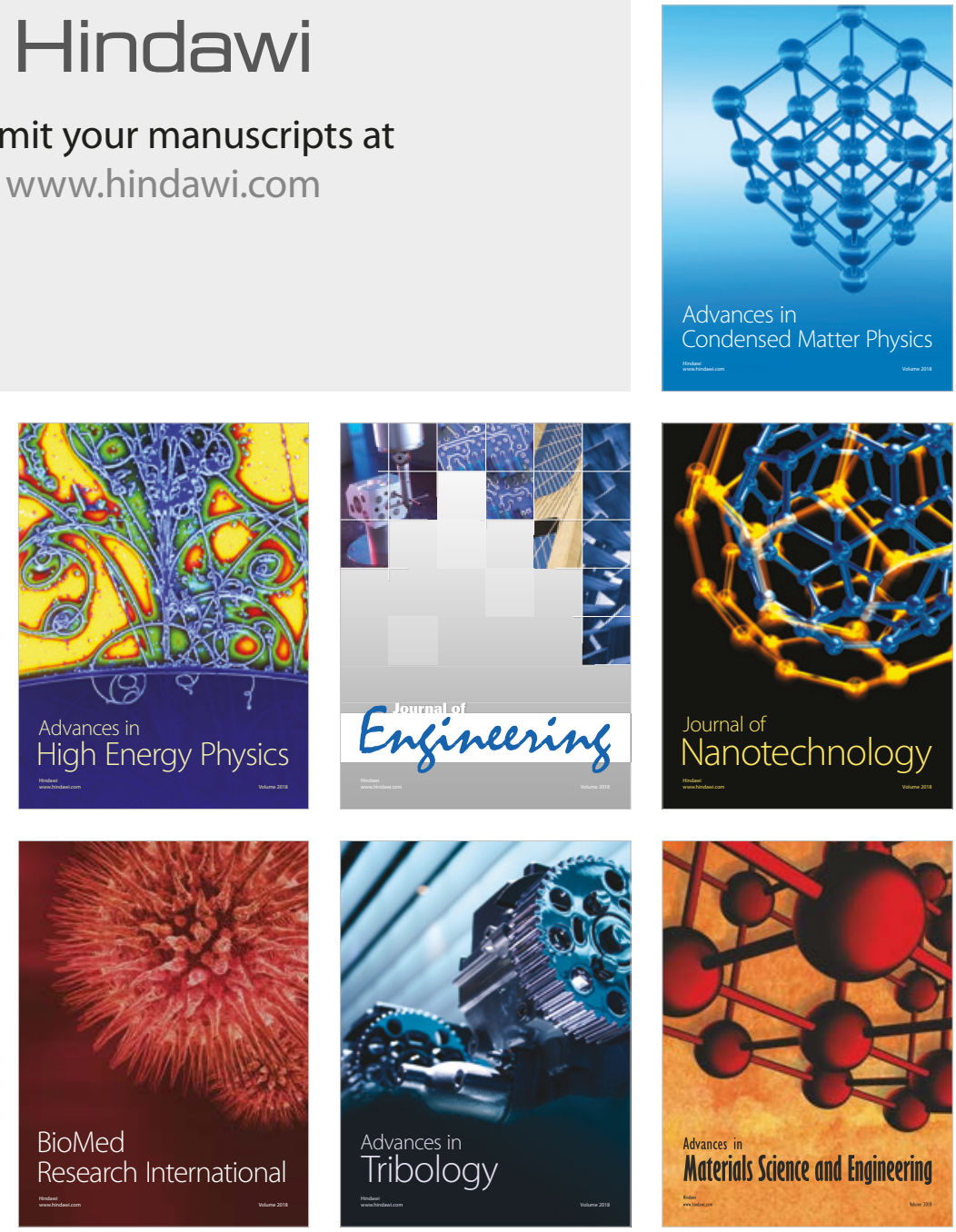